\title{
Clinical experiences and predictors of success of treatment with vedolizumab in IBD patients: a cohort study
}

\author{
Laura Mühl, Emily Becker, Tanja M. Müller, Raja Atreya, Imke Atreya, Markus F. Neurath and Sebastian Zundler (1)
}

\begin{abstract}
Background: Vedolizumab has become a standard treatment for the inflammatory bowel diseases ulcerative colitis (UC) and Crohn's disease (CD). However, there is an ongoing debate on the ideal individual treatment algorithms and means to predict treatment response are not routinely established.
\end{abstract}

Aims: We aimed to describe our experiences with vedolizumab at a large German tertiary referral center and to identify clinical predictors of success of vedolizumab treatment.

Methods: We performed a retrospective single-center cohort study employing univariable and multivariable analyses as well as Kaplan-Meier analyses of persistence on treatment.

Results: $36 \%$ and $35 \%$ of the patients with UC and CD, respectively, reached clinical remission after 17 weeks. Patients with lower clinical disease activity were more likely to achieve remission. The median persistence on treatment was 33 months for UC and 29 months for CD.

Conclusion: Our study confirms that vedolizumab is an efficient option for the treatment of UC and CD. Clinical parameters of disease activity may help to predict the success of treatment.

Keywords: Inflammatory bowel diseases, Vedolizumab, Real-world data

\section{Background}

The choice of treatment options in inflammatory bowel diseases (IBD) is constantly growing [1]. However, due to primary non-response or secondary loss of response in a relevant part of the patients [2-5], many of them do still not achieve durable remission and suffer from disease symptoms and complications.

While the increasing number of therapeutic agents provides the opportunity to initiate further therapy lines with alternative compounds in these patients, more and more evidence indicates that the probability of treatment

\footnotetext{
*Correspondence: sebastian.zundler@uk-erlangen.de
}

Department of Medicine 1 and "Deutsches Zentrum Immuntherapie",

University Hospital Erlangen, Friedrich-Alexander-Universität Erlangen-

Nürnberg, Ulmenweg 18, 91054 Erlangen, Germany success steeply declines with each line of treatment [6]. This observation underscores the necessity to choose the right treatment for individual patients early on to optimize their long-term outcomes and to reduce healthcare costs [7]. However, head-to-head comparative studies on the efficacy of the available therapies are scarce [8] and, moreover, biomarkers to predict the individual probability of treatment success have not been routinely established so far. Thus, evidence supporting individualized treatment strategies is largely lacking and preferences of the prescriber and the patient play a relevant role in therapy selection [9].

One of the standard therapy options for the treatment of both Crohn's disease (CD) and ulcerative colitis (UC) is the anti- $\alpha 4 \beta 7$ integrin antibody vedolizumab. Its efficacy and safety had been shown in large phase III trials in 
$2013[3,10]$ and confirmed in multiple real-world reports since then [11-14]. Vedolizumab has been shown to prevent the so-called gut homing process of $\alpha 4 \beta 7$-expressing immune cells, i.e. their extravasation from the blood to the intestinal tissue [15-17]. Probably due to this impact on circulating and not on resident immune cells, the onset of the effect is somewhat delayed in a considerable portion of the responding patients [10]. Therefore, vedolizumab is seen as a rather "slow-acting" antibody [18], further emphasizing the importance of a high a priori likelihood of success to avoid long ineffective treatment periods before the response or non-response can be reliably assessed.

While several potential biomarkers have been reported [19-21], such approaches require further validations before entering clinical practice. To the contrary, clinical characteristics of patients are easy to collect and may directly help to estimate outcomes. Thus, using clinical parameters for such purposes has been previously suggested [22].

Here, we retrospectively analyzed a cohort of patients treated with vedolizumab at a German tertiary referral center and performed an exploratory investigation of the ability of several routinely available parameters to predict the success of treatment. Overall, our data confirm that vedolizumab is an efficient option for the treatment of $\mathrm{UC}$ and $\mathrm{CD}$ and suggest that patients with less severe disease are more likely to enter remission. Thus, they further validate previous findings, while also providing important new aspects supporting the concept that treatment decisions for or against vedolizumab might be based on clinical patient characteristics.

\section{Methods}

\section{Study design}

We performed a single-center retrospective cohort study. All patients having received vedolizumab at the Department of Medicine 1 of the University Hospital Erlangen between June 2014 and May 2020 were identified. The individual patient data were collected from electronic patient records, anonymized and analyzed in accordance with the approval by the institution's Ethics Committee (Ethics Committee of the Friedrich-Alexander-University Erlangen-Nuremberg; 288_20Bc).

\section{Inclusion and exclusion criteria}

IBD patients aged $\geq 18$ years and receiving at least three applications of vedolizumab were screened for eligibility. Exclusion criteria were previous proctocolectomy, microscopic colitis, IBD-undefined (IBD-U), an active enteroor colostoma during the follow-up and an incomplete follow-up.

\section{Baseline parameters and outcomes}

Baseline was defined as the date of the first application of vedolizumab. The following baseline parameters were collected: age at disease onset, duration of disease, clinical disease activity as assessed by the 9-point partial Mayo score (PMS) [23] and the Harvey-Bradshaw-Index (HBI) [24] for UC and CD, respectively, disease extent (E and $\mathrm{L}$ category of the Montreal classification for UC and $\mathrm{CD}$, respectively), B category of the Montreal classification for CD patients, previous anti-TNF- $\alpha$ exposure, previous bowel surgery, current smoking status, endoscopic activity as assessed with the endoscopic Mayo score for $\mathrm{UC}$ and the simplified endoscopic score for CD (within 3 months prior to baseline), corticosteroid treatment of the first flare, concurrent steroid treatment and extraintestinal manifestations at baseline as well as the laboratory parameters $\mathrm{C}$-reactive protein (CRP), hemoglobin $(\mathrm{Hb})$ and leukocytes.

The primary endpoint of this study was clinical remission at the time of the fifth application of vedolizumab ( $17 \pm 0.5$ weeks). Clinical remission was defined as active treatment and a PMS $\leq 1$ for $\mathrm{UC}$ or an $\mathrm{HBI} \leq 4$ for $\mathrm{CD}$. As secondary endpoints, we analyzed corticosteroid-free clinical remission, i.e. a PMS $\leq 1$ or an $\mathrm{HBI} \leq 4$ for $\mathrm{UC}$ and $C D$, respectively, without concomitant steroid treatment at the time of the fifth application of vedolizumab, clinical remission and corticosteroid-free clinical remission for UC and CD after 1 year of treatment and endoscopic remission for UC defined as an endoscopic Mayo score $\leq 1$ at follow-up endoscopy (mean follow-up of $8.9 \pm 0.7$ months).

Additionally, we recorded, whether the patients stayed on treatment over a maximum follow-up of 3 years.

\section{Statistical analysis}

GraphPad Prism (GraphPad Software, Inc.) was used to perform statistical analyses.

Categorical variables are reported as frequencies and continuous variables as mean values with standard error of the mean (SEM) or range as indicated. In the univariable analyses, categorical variables were compared using Fisher's exact test (for frequencies $<5$ and contingency tables $>2 \times 2$ ) or Chi-square test (other cases) Continuous variables were compared using Mann-Whitney-U test for nonparametric data or unpaired $t$-test for parametric data.

In a second step, we built multivariable logistic regression prediction models for the UC and the CD cohort. Baseline clinical parameters with a p-value $<0.2$ on univariable analysis were included [25] after assessment for collinearity. The ability of the models to identify patients achieving the endpoints was analyzed with receiver-operator characteristic (ROC) analysis. 
Persistence on treatment in our cohort during 3 years after therapy initiation was visualized by calculation of "survival" probabilities with the Kaplan-Meier method. Comparisons were performed with the log-rank test.

Significance levels are indicated by asterisks $\left({ }^{*} \mathrm{p}<0.05\right.$; $\left.{ }^{* *} \mathrm{p}<0.01 ; * * \mathrm{p}<0.001\right)$

\section{Results}

\section{Patient demographics and efficacy of vedolizumab}

We identified 234 IBD patients that received vedolizumab at the Department of Medicine 1 of the University Hospital Erlangen from June 2014 to May 2020. After exclusion of 53 patients due to previous proctocolectomy $(n=10)$, IBD-U $(n=10)$, microscopic colitis $(n=3)$, active enteroor colostoma $(n=12)$ or incomplete follow-up $(n=18)$, 181 patients were included into the analysis, 106 with UC and 75 with CD (Fig. 1).

Baseline characteristics of the patient cohort are summarized in Table 1. Most patients received intensified treatment (mean application interval from application 3 to 5 was 4.8 weeks for UC and 4.7 weeks for CD) due to lack of response or primary application of an escalated regimen.

$36 \%$ of the patients with UC and $35 \%$ of the patients with $\mathrm{CD}$ met the primary endpoint of clinical remission at week $17 \pm 0.5$ and short-term steroid-free

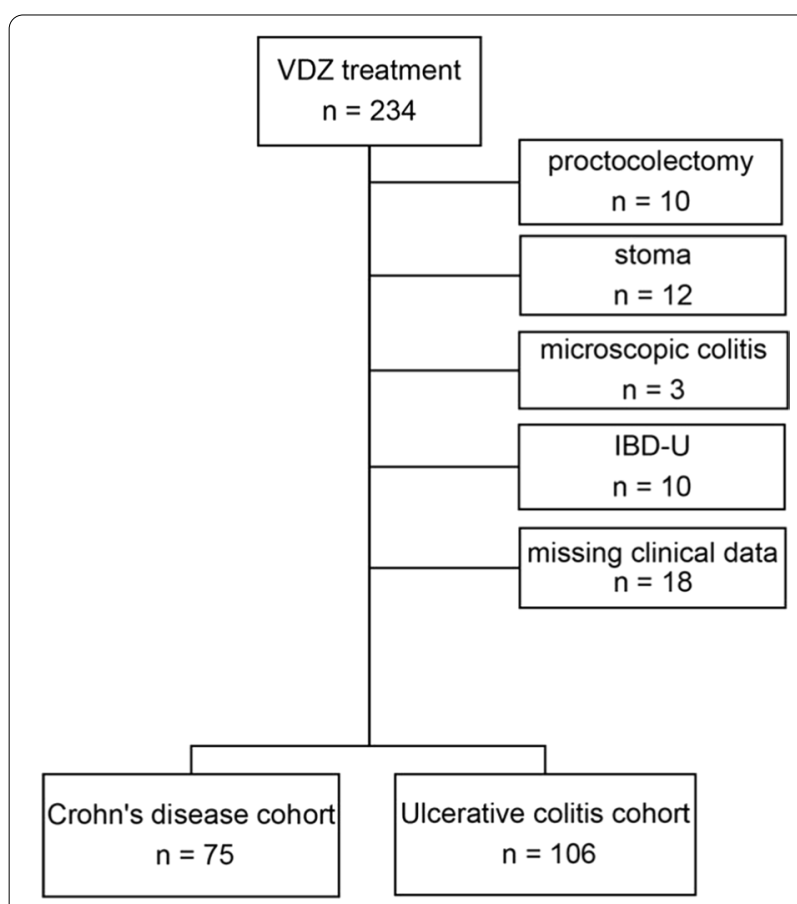

Fig. 1 Patient inclusion and exclusion chart. From 234 eligible patients 53 had to be excluded as indicated on the right. 106 patients with UC and 75 patients with CD were included into the analyses clinical remission was achieved by $29 \%$ of the patients with UC and CD. $71 \%$ and $64 \%$ of the patients with $\mathrm{UC}$ and $\mathrm{CD}$, respectively, which received continued vedolizumab therapy and for which data were available achieved clinical remission after 1 year. Long-term corticosteroid-free clinical remission was achieved by $68 \%$ and $56 \%$ of the patients. $45 \%$ of the patients with UC had endoscopic remission during follow up (mean $8.9 \pm 0.7$ months) (Table 2).

\section{Baseline clinical disease activity and hemoglobin levels are associated with induction of remission in UC}

We evaluated the association of the collected baseline parameters with success of therapy as assessed by the endpoints clinical remission, steroid-free clinical remission and endoscopic remission in univariable analyses.

In patients with $\mathrm{UC}$, baseline $\mathrm{Hb}$ levels were significantly higher in patients achieving clinical remission than in patients not achieving clinical remission. Moreover, baseline clinical disease activity as assessed by the 9-point PMS was significantly lower in patients that entered clinical remission compared with those who did not (Table 3). Similarly, with regard to steroidfree clinical remission, $\mathrm{Hb}$ was higher in remitters than in non-remitters, while the difference in PMS shortly missed significance (Additional file 1: Table 1). Moreover, lower PMS scores were significantly associated with clinical remission (Additional file 1: Table 2) and almost significantly associated with steroid-free clinical remission (Additional file 1: Table 3) after 1 year of treatment. Likewise, it was significantly lower in patients achieving vs. not achieving endoscopic remission during follow-up (Additional file 1: Table 4).

We incorporated all parameters with a p-value $<0.2$ into multivariable logistic regression models. Here, clinical disease activity at baseline emerged as independent predictor for short-term clinical remission (Table 4), while both $\mathrm{Hb}$ and PMS independently predicted short-term steroid-free clinical remission and PMS independently predicted endoscopic remission. No parameter reached significance with regard to longterm clinical outcomes (Additional file 1: Table 5).

In a ROC analysis of the multivariable model to predict short-term clinical remission, our model achieved an area under the curve (AUC) of 0.76 with a negative predictive power of $71.7 \%$ and a positive predictive power of $71.4 \%$ (Fig. 2).

\section{Baseline clinical disease activity predicts induction of clinical remission in CD}

Similarly, we performed univariable analyses to identify associations between the clinical baseline parameters and 
Table 1 Baseline characteristics of patients with Crohn's disease (CD) and Ulcerative colitis (UC)

\begin{tabular}{|c|c|c|}
\hline & Patients with CD & Patients with UC \\
\hline Disease duration from initial diagnosis (years) & $12.9(0.5-44.3)$ & $8.3(0.1-51.3)$ \\
\hline Age at initial diagnosis (years) & $25.5(10.5-66.8)$ & $34(4.0-77.3)$ \\
\hline Female (\%) & $47 / 75(63)$ & $46 / 106(43)$ \\
\hline CRP (mg/L) & $11(0.2-78.3)$ & $8.5(0.2-62.8)$ \\
\hline $\mathrm{Hb}(\mathrm{g} / \mathrm{dL})$ & $12.9(9.1-16.5)$ & $12.7(7.5-16.8)$ \\
\hline Leukocytes $\times 10^{3} / \mu \mathrm{L}$ & $9.9(3.6-20)$ & $9.3(2.4-22.5)$ \\
\hline Endoscopic disease activity* & $13.3(0-26)$ & $2.3(0-3)$ \\
\hline Clinical disease activity** & $7.03(0-22)$ & $4(0-8)$ \\
\hline \multirow[t]{3}{*}{ Disease extent $(\%)^{* * *}$} & L1: 15/75 (20) & E1:7/104 (7) \\
\hline & L2: 10/75 (13) & E2: 51/104 (49) \\
\hline & L3: 50/75 (67) & E3: 46/104 (44) \\
\hline First flare treated with corticosteroids (\%) & 63/73 (86) & $86 / 102(84)$ \\
\hline Previous treatment with anti TNF-a antibody (\%) & $67 / 75(89)$ & 79/105 (75) \\
\hline \multirow[t]{3}{*}{ Number of previous anti TNF-a antibodies (\%) } & 1: 14/67 (21) & $1: 43 / 79(54)$ \\
\hline & 2: 52/67 (78) & 2: $31 / 79(39)$ \\
\hline & 3: 1/67 (1) & $3: 5 / 79(6)$ \\
\hline Active smoking (\%) & $21 / 75(28)$ & $8 / 105(8)$ \\
\hline Concomitant corticosteroid therapy (\%) & $42 / 74(57)$ & $53 / 101(52)$ \\
\hline \multirow[t]{3}{*}{ Concomitant immunosuppressant use (\%) } & Azathioprin: 3/74 (4) & Azathioprin: 6/102 (6) \\
\hline & 6-Mercaptopurin: 0/74 (0) & 6-Mercaptopurin: 2/102 (2) \\
\hline & MTX: 5/74 (7) & MTX: 0/102 (0) \\
\hline Prior bowel surgery (\%) & 22/75 (29) & $1 / 106(1)$ \\
\hline \multirow[t]{3}{*}{ CD phenotype*** $(\%)$} & B1: 18/75 (24) & \\
\hline & B2: 30/75 (40) & \\
\hline & B3: 27/75 (36) & \\
\hline Extraintestinal manifestations (\%) & $25 / 75(33)$ & 14/106 (13) \\
\hline
\end{tabular}

Data are presented as mean (minimal value-maximal value) or frequencies (\%)

* Endoscopic Mayo score for UC, simplified endoscopic score for Crohn's disease (SES-CD) for CD

** PMS (partial Mayo score) for UC, HBI (Harvey Bradshaw-Index) for CD

*** According to the Montreal classification

Table 2 Efficacy of vedolizumab

\begin{tabular}{|c|c|c|c|c|c|}
\hline & \multicolumn{2}{|c|}{ Patients with clinical remission (\%) } & \multicolumn{2}{|c|}{ Patients with corticosteroid-free remission (\%) } & \multirow{2}{*}{$\begin{array}{l}\text { Patients } \\
\text { with endoscopic } \\
\text { remission (\%) } \\
\text { Month } 8.9 \pm 0.7\end{array}$} \\
\hline & Week $17 \pm 0.5$ & 1 year & Week $17 \pm 0.5$ & 1 year & \\
\hline UC & $38 / 106(36)$ & $40 / 56(71)$ & $31 / 106(29)$ & $38 / 56(68)$ & $29 / 64(45)$ \\
\hline$C D$ & $26 / 75(35)$ & $16 / 25(64)$ & $22 / 75(29)$ & $14 / 25(56)$ & \\
\hline
\end{tabular}

clinical remission or steroid-free remission in patients with CD.

Consistent with the observations for UC, baseline clinical disease activity measured with the HBI was significantly lower in patients entering remission early during vedolizumab treatment than in patients with persisting clinical disease activity. Moreover, previous anti-TNF- $\alpha$ antagonist exposure was higher in patients with non-remission (Table 5). Both parameters were also significantly different between patients achieving short-term steroid-free clinical remission and no steroid-free clinical remission. Here, additionally and not surprisingly, concomitant steroid treatment at baseline was substantially higher in those not achieving steroidfree remission (Additional file 1: Table 6). Hb levels closely missed significance regarding both endpoints 
Table 3 Clinical remission at week $17 \pm 0.5$ : univariable analysis of baseline parameters in patients with UC

\begin{tabular}{|c|c|c|c|c|}
\hline & $\begin{array}{l}\text { UC patients with clinical } \\
\text { remission }\end{array}$ & $\begin{array}{l}\text { UC patients with no clinical } \\
\text { remission }\end{array}$ & p-value & \\
\hline Disease duration from initial diagnosis (years) & $10.0 \pm 1.4$ & $7.4 \pm 1.1$ & 0.09 & M \\
\hline Age at initial diagnosis (years) & $35.7 \pm 2.4$ & $32.7 \pm 1.8$ & 0.31 & M \\
\hline $\mathrm{CRP}(\mathrm{mg} / \mathrm{L})$ & $10.5 \pm 2.4$ & $7.6 \pm 1.4$ & 0.36 & M \\
\hline $\mathrm{Hb}(\mathrm{g} / \mathrm{dL})$ & $13.3 \pm 0.4$ & $12.4 \pm 0.3$ & 0.04 & M \\
\hline Leukocytes $\times 10^{3} / \mu \mathrm{L}$ & $9.3 \pm 0.5$ & $9.4 \pm 0.5$ & 0.82 & M \\
\hline Endoscopic disease activity & $2.3 \pm 0.2$ & $2.3 \pm 0.1$ & 0.99 & M \\
\hline Clinical disease activity (PMS) & $3.5 \pm 0.3$ & $4.4 \pm 0.2$ & 0.02 & M \\
\hline Disease extent (E1/E2/E3)/n (\%) & $(2 / 22 / 14) / 38(5 / 58 / 37)$ & $(5 / 28 / 31) / 64(8 / 44 / 48)$ & 0.38 & c \\
\hline First flare treated with corticosteroids (\%) & $34 / 37(92)$ & $50 / 63(79)$ & 0.16 & $\mathrm{~F}$ \\
\hline Previous treatment with anti TNF-a antibody (\%) & $27 / 38(71)$ & $50 / 65(77)$ & 0.64 & $\mathrm{~F}$ \\
\hline Active smoking (\%) & $2 / 37(5)$ & $6 / 66(9)$ & 0.71 & $\mathrm{~F}$ \\
\hline Concomitant corticosteroid therapy (\%) & 20/37 (54) & $32 / 61(53)$ & $>0.99$ & $\mathrm{~F}$ \\
\hline Prior bowel surgery (\%) & $0 / 38(0)$ & $1 / 66(2)$ & $>0.99$ & $\mathrm{~F}$ \\
\hline Extraintestinal manifestations (\%) & $5 / 38(13)$ & $9 / 68(13)$ & $>0.99$ & $\mathrm{~F}$ \\
\hline
\end{tabular}

Data are presented as mean \pm standard error of mean or frequencies (\%)

M Mann-Whitney-U test

C Chi-square test

F Fisher exact test

\begin{tabular}{lcllll}
$\begin{array}{l}\text { Table } 4 \\
\text { in patients with UC }\end{array}$ & logistic & regression & analysis \\
\hline Parameter & OR & $\mathbf{9 5 \%} \mathbf{C l}$ & p-value & \\
\hline $\begin{array}{l}\text { Clinical remission at week } 17 \pm 0.5 \\
\begin{array}{l}\text { Disease duration from initial } \\
\text { diagnosis }\end{array}\end{array}$ & 1 & 0.1 to 1.01 & 0.11 & ns \\
$\mathrm{Hb}[\mathrm{g} / \mathrm{dL}]$ & 1.27 & 1.00 to 1.66 & 0.06 & $\mathrm{~ns}$ \\
$\begin{array}{l}\text { Clinical disease activity } \\
\text { First flare treated with corticoster- } \\
\text { oids }\end{array}$ & 0.71 & 0.52 to 0.95 & 0.03 & $*$ \\
\hline
\end{tabular}

OR odds ratio

and were numerically higher in patients entering remission and steroid-free remission. While no significant associations could be identified for clinical remission after 1 year (Additional file 1: Table 7), patients achieving corticosteroid-free clinical remission after 1 year were, on average, younger and had a longer disease duration (Additional file 1: Table 8).

Again, we built a multivariable logistic regression model. As in UC, baseline clinical disease activity independently predicted short-term clinical remission (Table 6). The achievement of short-term steroid-free clinical remission was independently associated with previous anti-TNF- $\alpha$ exposure and the age at initial

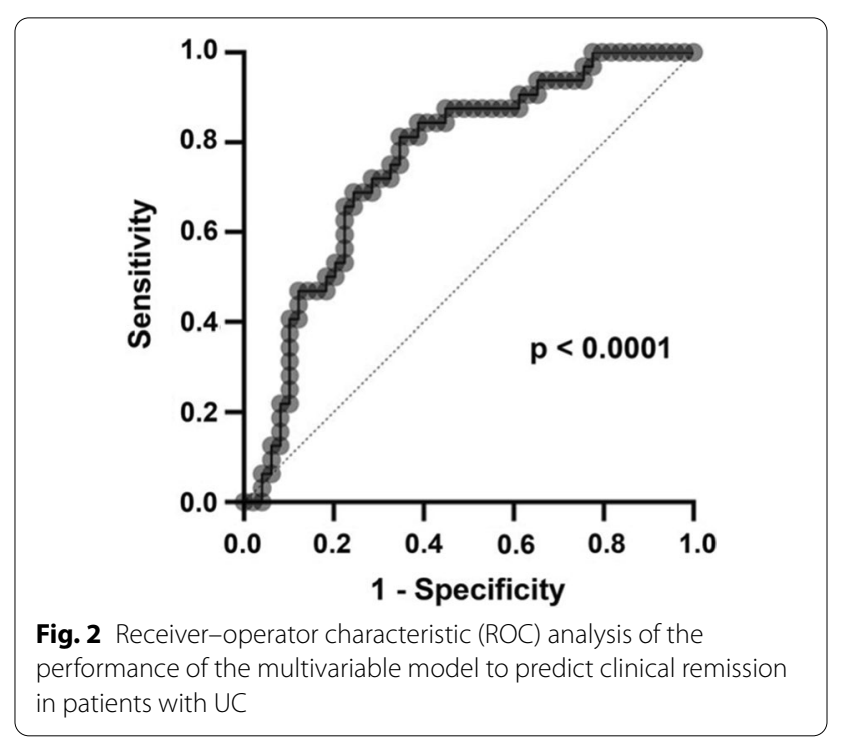

diagnosis, while no parameter significantly associated with outcomes after 1 year (Additional file 1: Table 9).

The AUC of our multivariable model to predict shortterm clinical remission in CD in a ROC analysis was 0.84 . The negative and positive predictive power were $81.4 \%$ and $66.7 \%$, respectively (Fig. 3 ). 
Table 5 Clinical remission at week $17 \pm 0.5$ : univariable analysis of baseline parameters in patients with CD

\begin{tabular}{lllc}
\hline & $\begin{array}{l}\text { CD patients with clinical } \\
\text { remission }\end{array}$ & $\begin{array}{l}\text { CD patients with no clinical } \\
\text { remission }\end{array}$ & p-value \\
\hline Disease duration from initial diagnosis (years) & $11.8 \pm 1.9$ & $13.4 \pm 1.3$ & 0.42 \\
Age at initial diagnosis (years) & $28.8 \pm 2.8$ & $23.4 \pm 1.5$ & 0.09 \\
CRP (mg/L) & $7.0 \pm 1.4$ & $13.5 \pm 3.1$ & 0.43 \\
Hb (g/dL) & $13.5 \pm 0.4$ & $12.6 \pm 0.3$ & 0.05 \\
Leukocytes $\times 10^{3} / \mathrm{ML}$ & $8.9 \pm 0.7$ & $10.4 \pm 0.7$ & $\mathrm{M}$ \\
Endoscopic disease activity & $14.4 \pm 1.4$ & $12.9 \pm 1.5$ & $\mathrm{M}$ \\
Clinical disease activity (HBl) & $5.9 \pm 0.8$ & $9.4 \pm 0.8$ & $\mathrm{M}$ \\
Disease extent (L1/L2/L3)/n (\%) & $(3 / 5 / 18) / 26(12 / 19 / 69)$ & $(11 / 5 / 31) / 47(23 / 11 / 66)$ & 0.58 \\
First flare treated with corticosteroids (\%) & $18 / 24(75)$ & $43 / 47(92)$ & 0.002 \\
Previous treatment with anti TNF-a antibody (\%) & $20 / 26(77)$ & $46 / 47(98)$ & 0.34 \\
Active smoking (\%) & $5 / 26(19)$ & $15 / 47(32)$ & $\mathrm{M}$ \\
Concomitant corticosteroid therapy (\%) & $12 / 26(46)$ & $28 / 44(64)$ & 0.08 \\
Prior bowel surgery (\%) & $7 / 26(27)$ & $15 / 47(32)$ & $\mathrm{F}$ \\
Phenotype (B1/B2/B3)/n (\%) & $(7 / 11 / 8) / 26(27 / 42 / 31)$ & $(11 / 18 / 18) / 47(24 / 38 / 38)$ & $\mathrm{F}$ \\
Extraintestinal manifestations (\%) & $18 / 26(27)$ & $\mathrm{F}$ \\
\hline
\end{tabular}

Data are presented as mean \pm standard error of mean or frequencies (\%)

M Mann-Whitney-U test

U Unpaired t test

C Chi-square test

F Fisher exact test

Table 6 Multivariable logistic regression analysis in patients with CD

\begin{tabular}{|c|c|c|c|c|}
\hline Parameter & OR & $95 \% \mathrm{Cl}$ & p-value & \\
\hline \multicolumn{5}{|l|}{ Clinical remission at week $17 \pm 0.5$} \\
\hline Age at initial diagnosis (years) & 1.06 & $0.99-1.13$ & 0.09 & ns \\
\hline $\mathrm{Hb}(\mathrm{g} / \mathrm{dl})$ & 1.30 & $0.79-2.23$ & 0.31 & ns \\
\hline Leukocytes $\times 10^{3} / \mathrm{ul}$ & 1.00 & $0.81-1.24$ & 0.98 & ns \\
\hline $\mathrm{HBI}$ & 0.82 & $0.68-0.96$ & 0.03 & * \\
\hline First flare treated with corticosteroids & 0.29 & $0.04-2.02$ & 0.22 & ns \\
\hline Previous treatment with anti TNF-a antibody & 0.06 & $0.002-1.09$ & 0.08 & ns \\
\hline
\end{tabular}

OR odds ratio

\section{Persistence on treatment with vedolizumab}

We also analyzed, for how long patients in our cohort continued to receive vedolizumab over a maximum follow-up of 3 years.

After 12 months, $78.9 \%$ of the patients with UC and $86.1 \%$ of the patients with CD further received vedolizumab treatment. After 24 months, this was the case in $63.9 \%$ and $56.1 \%$ of the UC and CD patients, respectively. And after 36 months, $42.6 \%$ of the UC patients and $28.4 \%$ of the $\mathrm{CD}$ patients persisted on treatment (Fig. 4). The median duration of therapy was 33 months for UC and 29 months for CD.

\section{Discussion}

Phase III clinical trials pose strict criteria for the inclusion and exclusion of patients resulting in treatment cohorts that do not always adequately reflect the patients later actually treated with the drugs investigated [26]. Hence, real-world reports are an important tool to assess, whether the data of the pivotal clinical studies translate to broader and less well selected populations. Several studies reporting real-world experiences with vedolizumab have been published so far [12, 27-29]. Although the endpoints employed in these studies slightly differed, our data fit into the overall 


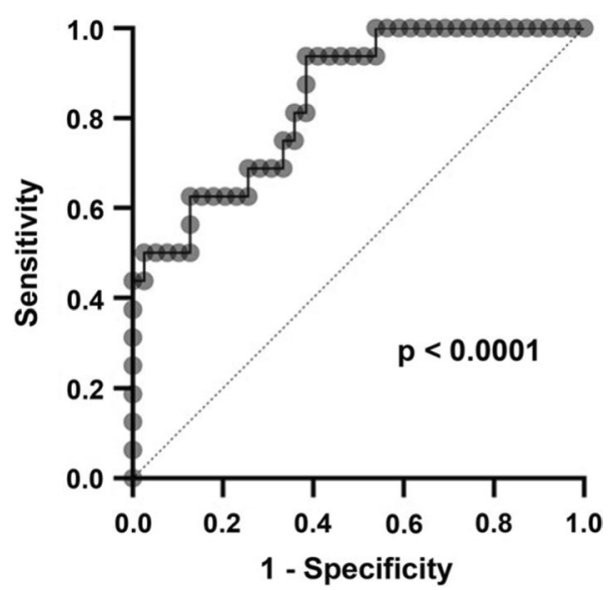

Fig. 3 Receiver-operator characteristic (ROC) analysis of the performance of the multivariable model to predict clinical remission in patients with $C D$

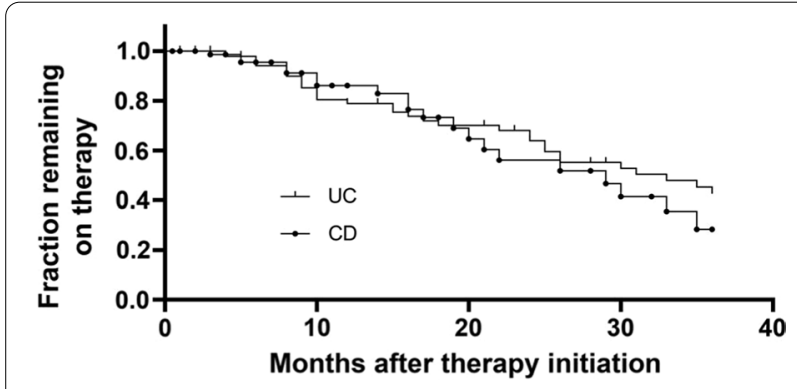

Fig. 4 Kaplan-Meier graph showing the persistence of patients with UC and CD on vedolizumab treatment

picture and the efficacy we observed is comparable to previous reports.

We report a median persistence on therapy of 33 and 29 months for UC and CD, respectively. This is comparable to what has been observed for first-line anti-TNF- $\alpha$ antibodies [30] and is remarkable, since a majority of our cohort was previously exposed to one or more biological therapies.

Prediction of the success of treatment is one of the major unmet needs in the field of IBD. With the sole exception of the recent head-to-head trial of vedolizumab vs. adalimumab in UC [8], there are no high-quality comparative data available that provide guidance for therapeutic decisions. Hence, evidence on the best choice of treatments and their optimal sequential use are largely lacking [31].

While further head-to-head studies would be suitable to address this aspect, it is not realistic that appropriate studies will be performed in near future to consistently answer this question in heterogeneous patient populations. Thus, alternative strategies to decide, which agent to use in which patient are needed.

Accordingly, several "biomarker strategies" have been suggested, e.g. assessment of intestinal antiTNF- $\alpha$ target cells by confocal laser endoscopy to predict response to adalimumab [32] or quantification of baseline $\alpha E$ expression in the gut to predict response to etrolizumab $[33,34]$. Such approaches have also been investigated with regard to vedolizumab. E.g., baseline microbial signatures were associated with the success of treatment [20], while transcriptomic signatures failed to predict outcomes [35]. Our group had observed that dynamic adhesion of peripheral blood $\mathrm{CD} 4^{+} \mathrm{T}$ cells to MAdCAM-1 in vitro and early changes in the expression of $\alpha 4 \beta 1$ integrin on circulating $C D 4^{+} \mathrm{T}$ cells correlate with clinical response [21,36,37].

However, those strategies will require substantial additional efforts before entering clinical practice and will, therefore, not be available in the near future. Consistently, predicting treatment success based on clinical patient characteristics has previously been suggested as an alternative [38, 39] and several studies have reported clinical parameters associating with different endpoints of treatment with vedolizumab. Stallmach et al. reported the absence of prior anti-TNF- $\alpha$ treatment and minimal steroid therapy before the initiation of vedolizumab as predictors of clinical remission of UC at week 54 [29]. In a US real-world report, CRP levels $>/=8.0 \mathrm{mg} / \mathrm{L}$ were negatively associated with clinical response and remission at week 14 [40]. Moreover, mild clinical disease activity at baseline predicted clinical remission of CD at week 14 in an Israeli multicenter cohort [13]. A US consortium reported prior anti-TNF- $\alpha$ exposure as negative predictor of remission in both CD and UC and of response in UC. Additionally, active or historical smoking, severe baseline disease activity and active perineal disease made clinical remission of CD less likely [28, 41]. Chaparro et al. showed that mild disease activity of UC was associated with higher probability of clinical remission of UC at week 14, whereas high CRP resulted in lower probability. Similarly, higher baseline HBI scores reduced the probability of clinical remission of CD at week 14 [42]. This was also resembling the observations of Baumgart et al., who reported low HBI scores and the absence of hospitalization in the year prior to treatment initiation to predict clinical remission of CD at week 14 [43]. And in the French GETAID cohort, corticosteroid use at induction and an HBI score $>10$ were negative predictors of steroid-free clinical remission of CD at week 14 and 54, while a Mayo score $>9$ at induction was a negative predictor of steroid-free clinical remission of UC at week 14 and 54 [11, 27]. Altogether, these reports 
strengthen the concept that patients with milder disease activity are more likely to benefit from therapy with vedolizumab.

Our study confirms and endorses these observations, since, consistently, lower HBI or PMS scores were associated with short-term clinical remission and steroid-free clinical remission in UC and CD and long-term clinical remission and endoscopic remission in UC. It is evident that our study has some important limitations, such as retrospective single-center design potentially implying bias to our data as well as limiting the data basis for long-term analyses, and unavailability of a validation cohort for the multivariable models. However, it contributes another important piece to the puzzle and helps to draw a clearer picture of the clinical use of vedolizumab. A previously not reported aspect we observed is that $\mathrm{Hb}$, a broadly available parameter, which is probably reflecting rectal bleeding and, thus, mucosal integrity in this scenario, seems to be a parameter helping to assess the probability of achieving remission.

Both for CD and UC, clinical decision support tools deriving from similar analyses in the phase III studies and validated in other real-world populations have previously been published $[39,44,45]$. Although it is clear that they rely on data of higher quality, a potential disadvantage of those models is that they require information on endoscopic disease activity. Our prediction models had acceptable AUCs purely based on clinical parameters. However, validation in independent populations is required.

Of note, increased response rates in patients with milder disease activity are not an exclusive feature of vedolizumab, but have also been observed with other antibodies like ustekinumab [38]. This leads to the question, how far predictors identified in this and other studies are able to actually support treatment decisions by weighing the balance towards one or the other treatment option or whether they are just a surrogate of a more or less refractory disease course [46]. The answer to this question is still open. This will require further and broader prospective studies including patients treated with different therapeutic options. For the moment, clinicians need to rely on gradual differences in the predictive clinical parameters as well as taking into account safety aspects, extraintestinal manifestations or the route of administration.

\section{Conclusion}

In our cohorts of UC and CD patients, the efficacy of vedolizumab in inducing clinical and steroid-free remission was comparable to previous reports. Median persistence on therapy was almost 3 years. Lower clinical disease activity was associated with improved outcomes.
Taken together, our data may help to better understand the role of vedolizumab in treatment algorithms and to support treatment decisions.

\section{Supplementary information}

The online version contains supplementary material available at https://doi. org/10.1186/s12876-021-01604-z.

Additional file 1. Univariable and multivariable analyses for secondary endpoints.

\section{Abbreviations}

AUC: Area under the curve; BSA: Bovine serum albumin; CD: Crohn's disease; CRP: C-reactive protein; HBI: Harvey-Bradshaw index; IBD: Inflammatory bowel disease; MAdCAM-1: Mucosal addressin vascular cell adhesion molecule 1:; PBMCs: Peripheral blood mononuclear cells; PMS: Partial Mayo score; rh: Recombinant human; ROC: Receiver operator characteristics; SEM: Standard error of the mean; TNF-a: Tumor necrosis factor alpha; UC: Ulcerative colitis; VDZ: Vedolizumab.

\section{Acknowledgements}

The research of RA, IA, MFN and SZ was supported by the Interdisciplinary Center for Clinical Research (IZKF) and the ELAN program of the University Erlangen-Nuremberg, the Else Kröner-Fresenius-Stiftung, the Fritz BenderStiftung, the Dr Robert Pfleger Stiftung, the Litwin IBD Pioneers Initiative of the Crohn's and Colitis Foundation of America (CCFA), the Kenneth Rainin Foundation, the Ernst Jung-Stiftung for Science and Research, the German Crohn's and Colitis Foundation (DCCV) and the German Research Foundation (DFG) through individual grants (ZU 377/4-1) and the Collaborative Research Centers TRR241, 643, 796 and 1181. The present work was performed in fulfillment of the requirements for obtaining the degree "Dr. med. dent." for LM and in partial fulfillment of the requirements for obtaining the degree "Dr. rer. biol. hum." for SZ. The authors thank Julia Derdau, Monique Slawik, Julia Schuster and Dorothee Dziony for excellent technical assistance.

\section{Authors' contributions}

LM collected the clinical data. LM, EB, TM, RA, IA, MFN and SZ analyzed and interpreted the data; LM and SZ drafted the manuscript. All authors read and approved the final manuscript.

\section{Funding}

Open Access funding enabled and organized by Projekt DEAL. German Research Foundation (DFG, ZU 377/4-1), Interdisciplinary Center for Clinical Research (IZKF) of the University Erlangen-Nuremberg (J63, A84).

\section{Availability of data and materials}

The datasets generated and analyzed during the current study are available from the corresponding author on reasonable request.

\section{Ethics approval and consent to participate}

All patients gave informed written consent for the study. The procedures were approved by the institution's ethics committee (Ethics Committee of the Friedrich-Alexander-University Erlangen-Nuremberg; 288_20BC).

\section{Consent for publication}

Not applicable.

\section{Competing interests}

S.Z. received honoraria from Takeda and Roche. M.F.N. has served as an advisor for Pentax, Giuliani, MSD, Abbvie, Janssen, Takeda and Boehringer. M.F.N. and

S.Z. received research support from Takeda, Roche and Shire.

Received: 25 August 2020 Accepted: 7 January 2021

Published online: 22 January 2021 


\section{References}

1. Neurath MF. Current and emerging therapeutic targets for IBD. Nat Rev Gastroenterol Hepatol. 2017:14:269-78.

2. Colombel JF, Sandborn WJ, Reinisch W, et al. Infliximab, azathioprine, or combination therapy for Crohn's disease. N Engl J Med. 2010;362:1383-95.

3. Feagan BG, Rutgeerts P, Sands BE, et al. Vedolizumab as induction and maintenance therapy for ulcerative colitis. N Engl J Med. 2013:369:699-710.

4. Feagan BG, Sandborn WJ, Gasink C, et al. Ustekinumab as induction and maintenance therapy for Crohn's disease. N Engl J Med. 2016:375:1946-60.

5. Danese S, Vuitton L, Peyrin-Biroulet L. Biologic agents for IBD: practical insights. Nat Rev Gastroenterol Hepatol. 2015;12:537-45.

6. Yanai $\mathrm{H}$, Hanauer SB. Assessing response and loss of response to biological therapies in IBD. Am J Gastroenterol. 2011;106:685-98.

7. Yu H, Maclsaac D, Wong JJ, Sellers ZM, Wren AA, Bensen R, Kin C, Park KT. Market share and costs of biologic therapies for inflammatory bowe disease in the USA. Aliment Pharmacol Ther. 2018;47:364-70.

8. Sands BE, Peyrin-Biroulet L, Loftus EV, et al. Vedolizumab versus adalimumab for moderate-to-severe ulcerative colitis. N Engl J Med. 2019;381:1215-26.

9. Chan W, Kariyawasam VC, Kim S, Pudipeddi AV, Paramsothy S, Shim $\mathrm{HH}$, Mourad FH, Ding N, Ferrante M, Leong RW. Gastroenterologists preference and risk perception on the use of immunomodulators and biological therapies in elderly patients with ulcerative colitis: an international survey. Eur J Gastroenterol Hepatol. 2020. https://doi.org/10.1097/ MEG.0000000000001768.

10. Sandborn WJ, Feagan BG, Rutgeerts P, et al. Vedolizumab as induction and maintenance therapy for Crohn's disease. N Engl J Med. 2013:369:711-21

11. Amiot A, Grimaud J-C, Peyrin-Biroulet $L$, et al. Effectiveness and safety of vedolizumab induction therapy for patients with inflammatory bowel disease. Clin Gastroenterol. 2016. https://doi.org/10.1016/j. cgh.2016.02.016.

12. Baumgart DC, Bokemeyer B, Drabik A, Stallmach A, Schreiber S, Vedolizumab Germany Consortium. Vedolizumab induction therapy for inflammatory bowel disease in clinical practice-a nationwide consecutive German cohort study. Aliment Pharmacol Ther. 2016;43:1090-102.

13. Kopylov U, Ron Y, Avni-Biron I, et al. Efficacy and safety of vedolizumab for induction of remission in inflammatory bowel disease-the Israeli realworld experience. Inflamm Bowel Dis. 2017:23:404-8.

14. Narula N, Peerani F, Meserve J, et al. Vedolizumab for ulcerative colitis: treatment outcomes from the VICTORY consortium. Am J Gastroenterol. 2018;113:1345.

15. Zundler S, Becker E, Schulze LL, Neurath MF. Immune cell trafficking and retention in inflammatory bowel disease: mechanistic insights and therapeutic advances. Gut. 2019;68:1688-700.

16. Zundler S, Klingberg A, Schillinger D, Fischer S, Neufert C, Atreya I, Gunzer M, Neurath MF. Three-dimensional cross-sectional light-sheet microscopy imaging of the inflamed mouse gut. Gastroenterology. 2017;153:898-900.

17. Schleier L, Wiendl M, Heidbreder K, et al. Non-classical monocyte homing to the gut via a4 37 integrin mediates macrophage-dependent intestinal wound healing. Gut. 2020;69:252-63.

18. Sandborn WJ. The present and future of inflammatory bowel disease treatment. Gastroenterol Hepatol. 2016;12:438-41.

19. Verstockt B, Verstockt S, Veny M, Dehairs J, Arnauts K, Van Assche G, De Hertogh G, Vermeire S, Salas A, Ferrante M. Expression levels of 4 genes in colon tissue might be used to predict which patients will enter endoscopic remission after vedolizumab therapy for inflammatory bowel diseases. Clin Gastroenterol Hepatol. 2020;18:1142-1151.e10.

20. Ananthakrishnan AN, Luo C, Yajnik V, Khalili H, Garber JJ, Stevens BW, Cleland T, Xavier RJ. Gut microbiome function predicts response to anti-integrin biologic therapy in inflammatory bowel diseases. Cell Host Microbe. 2017;21:603-610.e3.

21. Allner C, Melde M, Becker E, et al. Baseline levels of dynamic CD4+T cell adhesion to MAdCAM-1 correlate with clinical response to vedolizumab treatment in ulcerative colitis: a cohort study. BMC Gastroenterol. 2020;20:103.
22. Meserve J, Dulai P. Predicting response to vedolizumab in inflammatory bowel disease. Front Med. 2020. https://doi.org/10.3389/ fmed.2020.00076.

23. Lewis JD, Chuai S, Nessel L, Lichtenstein GR, Aberra FN, Ellenberg JH. Use of the non-invasive components of the mayo score to assess clinical response in ulcerative colitis. Inflamm Bowel Dis. 2008;14:1660-6.

24. Harvey RF, Bradshaw JM. A simple index of Crohn's-disease activity. Lancet. 1980;1:514

25. Nakashima H, Imagama S, Yukawa Y, et al. Multivariate analysis of C-5 palsy incidence after cervical posterior fusion with instrumentation: Clinical article. J Neurosurg Spine. 2012;17:103-10.

26. Suvarna VR. Real world evidence (RWE) - Are we (RWE) ready? Perspect Clin Res. 2018:9:61-3.

27. Amiot A, Serrero M, Peyrin-Biroulet $L$, et al. One-year effectiveness and safety of vedolizumab therapy for inflammatory bowel disease: a prospective multicentre cohort study. Aliment Pharmacol Ther. 2017:46:310-21.

28. Dulai PS, Singh $S$, Jiang $X$, et al. The real-world effectiveness and safety of vedolizumab for moderate-severe Crohn's disease: results from the US VICTORY consortium. Am J Gastroenterol. 2016:111:1147-55.

29. Stallmach A, Langbein C, Atreya R, et al. Vedolizumab provides clinical benefit over 1 year in patients with active inflammatory bowel diseasea prospective multicenter observational study. Aliment Pharmacol Ther. 2016:44:1199-212.

30. Olivera P, Thiriet L, Luc A, Baumann C, Danese S, Peyrin-Biroulet L. Treatment persistence for infliximab versus adalimumab in Crohn's disease: a 14-year single-center experience. Inflamm Bowel Dis. 2017;23:976-85.

31. Harbord M, Eliakim R, Bettenworth D, et al. Third European evidencebased consensus on diagnosis and management of ulcerative colitis. Part 2: current management. J Crohns Colitis. 2017;11:769-84.

32. Atreya $\mathrm{R}$, Neumann $\mathrm{H}$, Neufert $\mathrm{C}$, et al. In vivo imaging using fluorescent antibodies to tumor necrosis factor predicts therapeutic response in Crohn's disease. Nat Med. 2014:20:313-8.

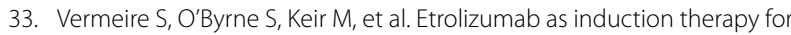
ulcerative colitis: a randomised, controlled, phase 2 trial. Lancet Lond Engl. 2014;384:309-18.

34. Tew GW, Hackney JA, Gibbons D, et al. Association between response to etrolizumab and expression of integrin aE and granzyme A in colon biopsies of patients with ulcerative colitis. Gastroenterology. 2016;150:477487.e9.

35. Arijs I, Hertogh GD, Lemmens B, et al. Effect of vedolizumab (anti-a4ß37integrin) therapy on histological healing and mucosal gene expression in patients with UC. Gut. 2018;67:43-52.

36. Binder $M-T$, Becker $E$, Wiendl $M$, et al. Similar inhibition of dynamic adhesion of lymphocytes from IBD patients to MAdCAM-1 by vedolizumab and etrolizumab-s. Inflamm Bowel Dis. 2018;24:1237-50.

37. Fuchs F, Schillinger D, Atreya R, Hirschmann S, Fischer S, Neufert C, Atreya I, Neurath MF, Zundler S. Clinical response to vedolizumab in ulcerative colitis patients is associated with changes in integrin expression profiles. Front Immunol. 2017. https://doi.org/10.3389/fimmu.2017.00764.

38. Dulai $P$, Guizzetti L, Ma T, Jairath $V$, Singh $S$, Feagan BG, Gasink C, Pires A Sandborn WJ. 637 clinical prediction model and decision support tool for ustekinumab in Crohn's disease. Am J Gastroenterol. 2019:114:S373.

39. Dulai PS, Boland BS, Singh S, et al. Development and validation of a scoring system to predict outcomes of vedolizumab treatment in patients with Crohn's disease. Gastroenterology. 2018;155:687-695.e10.

40. Shelton E, Allegretti JR, Stevens B, et al. Efficacy of vedolizumab as induction therapy in refractory IBD patients: a multicenter cohort. Inflamm Bowel Dis. 2015;21:2879-85

41. Dulai P, Meserve JD, Hartke JG, et al. Sa1853-predictors of clinical and endoscopic response with vedolizumab for the treatment of moderately-severely active ulcerative colitis: results from the US victory consortium. Gastroenterology. 2017;152:S371.

42. Chaparro M, Garre A, Ricart E, et al. Short and long-term effectiveness and safety of vedolizumab in inflammatory bowel disease: results from the ENEIDA registry. Aliment Pharmacol Ther. 2018:48:839-51.

43. Baumgart DC, Bokemeyer B, Drabik A, Stallmach A, Schreiber S. Vedolizumab induction therapy for inflammatory bowel disease in clinical practice - a nationwide consecutive German cohort study. Aliment Pharmacol Ther. 2016:43:1090-102. 
44. Dulai PS, Amiot A, Peyrin-Biroulet L, et al. A clinical decision support too may help to optimise vedolizumab therapy in Crohn's disease. Aliment Pharmacol Ther. 2020;51:553-64.

45. Dulai PS, Singh S, Casteele NV, et al. Development and validation of clinical scoring tool to predict outcomes of treatment with vedolizumab in patients with ulcerative colitis. Clin Gastroenterol Hepatol. 2020. https:// doi.org/10.1016/j.cgh.2020.02.010.

46. Verstockt B, Ferrante M. Editorial: a clinical decision tool to identify patients who might benefit most from intensified dosing in the biological era-getting nearer? Aliment Pharmacol Ther. 2020;51:737-8.

\section{Publisher's Note}

Springer Nature remains neutral with regard to jurisdictional claims in published maps and institutional affiliations.
Ready to submit your research? Choose BMC and benefit from:

- fast, convenient online submission

- thorough peer review by experienced researchers in your field

- rapid publication on acceptance

- support for research data, including large and complex data types

- gold Open Access which fosters wider collaboration and increased citations

- maximum visibility for your research: over $100 \mathrm{M}$ website views per year

At BMC, research is always in progress.

Learn more biomedcentral.com/submissions 